\title{
Exploring synergies and trade-offs among the sustainable development goals: collective action and adaptive capacity in marginal mountainous areas of India
}

\author{
Steven Orchard ${ }^{1}$ (D) Dominic Glover ${ }^{2} \cdot$ Shova Thapa Karki ${ }^{1} \cdot$ Seife Ayele $^{2} \cdot$ Debashish Sen $^{3} \cdot$ Roshan Rathod $^{3}$. \\ Pedram Rowhani ${ }^{1}$
}

Received: 27 February 2019 / Accepted: 28 November 2019 / Published online: 9 December 2019

(c) The Author(s) 2019

\begin{abstract}
Global environmental change (GEC) threatens to undermine the sustainable development goals (SDGs). Smallholders in marginal mountainous areas (MMA) are particularly vulnerable due to precarious livelihoods in challenging environments. Acting collectively can enable and constrain the ability of smallholders to adapt to GEC. The objectives of this paper are: (i) identify collective actions in four MMA of the central Indian Himalaya Region, each with differing institutional contexts; (ii) assess the adaptive capacity of each village by measuring livelihood capital assets, diversity, and sustainable land management practices. Engaging with adaptive capacity and collective action literatures, we identify three broad approaches to adaptive capacity relating to the SDGs: natural hazard mitigation (SDG 13), social vulnerability (SDG 1, 2 and 5), and social-ecological resilience (SDG 15). We then develop a conceptual framework to understand the institutional context and identify SDG synergies and trade-offs. Adopting a mixed method approach, we analyse the relationships between collective action and the adaptive capacity of each village, the sites where apparent trade-offs and synergies among SDGs occur. Results illustrate each village has unique socio-environmental characteristics, implying distinct development challenges, vulnerabilities and adaptive capacities exist. Subsequently, specific SDG synergies and trade-offs occur even within MMA, and it is therefore crucial that institutions facilitate locally appropriate collective actions in order to achieve the SDGs. We suggest that co-production in the identification, prioritisation and potential solutions to the distinct challenges facing MMA can increase understandings of the specific dynamics and feedbacks necessary to achieve the SDGs in the context of GEC.
\end{abstract}

Keywords Adaptive capacity $\cdot$ Collective action $\cdot$ Climate change adaptation $\cdot$ Sustainability $\cdot$ Social-ecological systems . Mountains

Handled by John Thompson, Institute of Development Studies, United Kingdom.

Electronic supplementary material The online version of this article (https://doi.org/10.1007/s11625-019-00768-8) contains supplementary material, which is available to authorized users.

Steven Orchard

s.e.orchard@sussex.ac.uk

1 Sussex Sustainability Research Programme, University of Sussex, Brighton, UK

2 Sussex Sustainability Research Programme, Institute of Development Studies, Brighton, UK

3 People's Science Institute, Dehra Dun, India

\section{Introduction}

The 2030 Agenda for Sustainable Development and the Paris Agreement on climate change acknowledge the benefits of strengthening linkages between climate and development. This is important as the risks associated with rapid global environmental change (GEC) threaten to undermine achievement of the sustainable development goals (SDGs) (GomezEcheverri 2018). Agriculture, which supports smallholder livelihoods in rural regions of the global south, both drives GEC through land use change and green-house gas emissions, and is also threatened by the effects of GEC, such 
as climate variability and extreme weather events (Reed et al. 2013). Smallholders are particularly vulnerable to the impacts of climatic events, such as flooding and droughts. Actions to enhance smallholder's capacity to adapt to GEC are crucial for achieving the SDGs (Butler et al. 2016).

Current research, policy and practice draw on three existing conceptual approaches that are likely to be useful for enhancing smallholder's adaptive capacity, namely: natural hazard mitigation, social vulnerability and social-ecological resilience (Eakin et al. 2009; Suckall et al. 2018). However, actions that support each approach entail inherent synergies and trade-offs in terms of spatial and temporal scale and social, economic and environmental goals and outcomes (Eakin et al. 2009). Assessment of the potential synergies and trade-offs between approaches and actions for sustainable development is considered one of the most pressing priorities for research for the SDGs (Nilsson et al. 2018). Understanding the range of positive and negative interactions among SDGs is key to unlocking their full potential, ensuring that progress made in some areas is not at the expense of progress in others (Nilsson et al. 2018).

Limited access to resources and poverty make smallholders around the globe vulnerable to GEC. Those in marginal mountainous areas (MMA) are particularly vulnerable due to precarious livelihoods located on steep slopes with typically difficult to cultivate, shallow soils with low fertility, making it difficult to cope with shocks and stresses (FAO 2015). These communities also face higher levels of climatic risks and natural hazards, such as earthquakes, in comparison to low-lying areas (IPCC 2014; FAO 2015). However, the unique challenges and characteristics of mountainous regions typically do not receive appropriate consideration in national and global development agendas (Jodha 2005). Nonetheless, governmental commitments to fulfil the 2030 Agenda and pledges to 'leave no one behind' hold promise for enhancing the adaptive capacity of smallholders in MMA whilst fostering sustainable mountain development (von Dach et al. 2016).

The ability of smallholders to adapt to GEC is enabled and constrained by their ability to act collectively (Adger 2003). Collective action occurs when groups of people cooperate and pool resources in order to achieve common interests and shared goals which could not be achieved individually (North 1990; Ostrom 1990). The adaptive capacity of smallholders is largely a function of how institutions shape, and are shaped by, collective actions to manage conflicting interests and distribute resources for natural hazard mitigation, social vulnerability and social-ecological resilience (Armitage 2005; Pelling and High 2005). Smallholder livelihoods and the institutions that facilitate resource distribution and cooperation are sites where the apparent trade-offs and synergies among SDGs are negotiated and resolved in practice. Whilst it is evident that institutions for collective action can act as an enabler for adaptive capacity and SDG achievement in the context of GEC (Bowen et al. 2017), how specific actions interact with SDGs remains unclear, particularly in the context of MMA (FAO 2015; Pandey et al. 2016).

The objectives of this paper are to: (i) identify collective actions in four remote villages of the central Indian Himalaya Region (CIHR), each with differing institutional arrangements; (ii) assess the adaptive capacity of each village by measuring livelihood capital assets, diversity, and sustainable land management (SLM) practices. Engaging with adaptive capacity and collective action literatures, we identify three broad approaches to adaptive capacity relating to the SDGs: natural hazard mitigation (SDG 13), social vulnerability (SDG 1,2 and 5), and social-ecological resilience (SDG 15). We then develop a conceptual framework to understand the institutional context and identify synergies and trade-offs among SDGS. The findings of this study will support research, policy and practice for more effective and efficient implementation of SDGs in MMA.

\section{Approaches to analysing adaptive capacity and inherent SDG interactions}

\section{Adaptive capacity}

Adaptive capacity has been defined by Bettini et al. (2015: 48) as "...the ability to mobilize and combine different capacities within a system, to anticipate or respond to economic, environmental, and social stressors, in order to initiate structural or functional change to a system and thereby achieve resilient or transformative adaptation". Adaptive capacity is defined by the thresholds and conditions which establish the range within which a system can accommodate, manage, adapt and recover from disturbance, which vary along with politico-institutional, socio-economic, and environmental factors (Smit and Wandel 2006). Institutional flexibility, diversity (e.g., of livelihood options, resources, networks, practices, institutions, etc.), experimentation, learning, and self-organisation are important components of adaptive capacity. However, the latent character of adaptive capacity makes it difficult to identify and measure until after it has been triggered by disturbance. Analysing how people have prepared and responded to past disturbances can provide insights into adaptive capacity (Eakin et al. 2014; Engle 2011; Fazey et al. 2016). Recent research attempts to analyse adaptive capacity have employed two complementary approaches (Thapa et al. 2016): asset-based approaches that highlight livelihood resources and capital assets (i.e., financial, human, social, physical and natural); and process-based approaches, which consider governance and the institutional arrangements that shape the access, mobilisation and utilisation of capital assets. 


\section{Asset-based adaptive capacity: livelihood resources}

Rural livelihoods are created through complex interactions among financial, human, social, physical and natural resources (Chambers and Conway 1992), and may be considered sustainable if they can be maintained without undermining the natural resource base (Scoones 1998). Smallholders endowed with greater access to and diversity of livelihood resources typically possess a greater capacity to adapt to GEC, thanks to their enhanced ability to shift and rebalance activities, and mobilise alternative resources, in order to plan, anticipate, react to and recover from multiple stressors (Reed et al. 2013) (Table 1). Conversely, livelihoods that are not diversified are likely to be less capable of managing risk and to have less adaptive capacity (Ellis 1998). To explore what could be required to strengthen adaptive capacity in the future, livelihood analysis can be used to investigate past livelihood strategies and activities of smallholders that were undertaken in order to navigate historical human-environment interactions and to manage risk, uncertainty and vulnerability (Gerlitz et al. 2017). The sustainable livelihoods approach resonates harmoniously with the SDGs agenda, which aspires to reduce inequality, limit ecological damage, and secure resilient livelihoods (Bowen et al. 2017), and with sustainability science, which increasingly focuses on identifying pathways to secure resilient livelihoods in the face of multiple stressors (Tanner et al. 2015).

Collective action can enhance asset-based adaptive capacity through actions that increase resource access for group members to draw upon, particularly during disturbance and distress (Thapa et al. 2016). For example, collective savings and credit provide access to economic resources to draw upon that reduce vulnerability during hardship (Ireland and Thomalla 2011). Likewise, the social networks that facilitate collective action can provide access to information vital for managing uncertainty and rapid change (Pelling and High 2005). Collective action can also provide access to pooled physical capital assets, and natural capital through commonly managed natural resources such as grazing land, water and forests (Ireland and Thomalla 2011).

\section{Process-based adaptive capacity: institutions}

Asset-based indices may not accurately measure adaptive capacity in the absence of process-based measures, which focus on the ways in which governance mechanisms and institutional dynamics determine access to and control of livelihood resources (Eakin et al. 2014). Institutions are defined here as the formal rules and informal norms, values and beliefs that govern individual behaviour (North 1990; Ostrom 1990). As described by Helmke and Levitsky (2004: p727), “...formal institutions are openly codified, in the sense that they are established and communicated through channels that are widely accepted as official...informal institutions are socially shared rules, usually unwritten, that are created, communicated, and enforced outside of officially sanctioned channels". Formal institutions are enabled and/ or constrained by informal institutions, and also shape and are shaped by social practices (Helmke and Levitsky 2004). GEC challenges institutions to enable society to manage disturbance whilst being flexible enough to change in light of new information (Gupta et al. 2010). However, institutions can be conservative, reactive and resistant to change due to cultures and ideologies that support certain rights, relations, practices and pathways while excluding others (Engle 2011; Ireland and Thomalla 2011). As such, institutions that could potentially enhance adaptive capacity through collective action are often constrained by the socio-political barriers that limit participation, sharing, learning and empowerment (Eakin et al. 2014). For example, competing priorities, insufficient resources, shortfalls of political will, corruption, lack of community engagement and weak participation all limit the effectiveness of collective action to enhance adaptive capacity (Gupta et al. 2010).

Adaptive capacity has been described as a type of capital asset that can only be put into play through appropriate institutions (Tompkins and Adger 2004). Local institutions (e.g., public authorities, civil society, private sector and community-based organisations) can enhance adaptive capacity by reducing uncertainty, ordering social relations, generating commonly understood codes of behaviour, building trust and creating norms of reciprocity, whereby collective action may be possible (North 1990). Collective action can increase access to the resources needed to sustain smallholder livelihoods in the face of disturbance and change by shaping institutional processes for managing common-pool resources (e.g., water, forests, pastures, etc.), resolving resource conflicts, reducing the cost of adaptive actions, and mediating the link between smallholders and external information and resources (Agrawal 2008; Cox 2014). Research shows how institutions can shape the social networks crucial for collective action to enhance adaptive capacity (and vice versa), enabling smallholders to work together to identify, discuss and solve problems, and be empowered to lobby for institutional change (Gupta et al. 2010).

\section{Adaptive capacity in marginal mountainous areas}

Smallholder livelihoods in MMA are characterised by challenges in accessing, mobilising and utilising limited resources (Mishra et al. 2019). Mountain landscapes typically comprise relatively young, fragile and growing formations of soft rock with numerous fault lines, fractures and crevices making them highly earthquake- and landslideprone (Goel 2014). Physical marginalisation results from geographic remoteness and topographic characteristics 


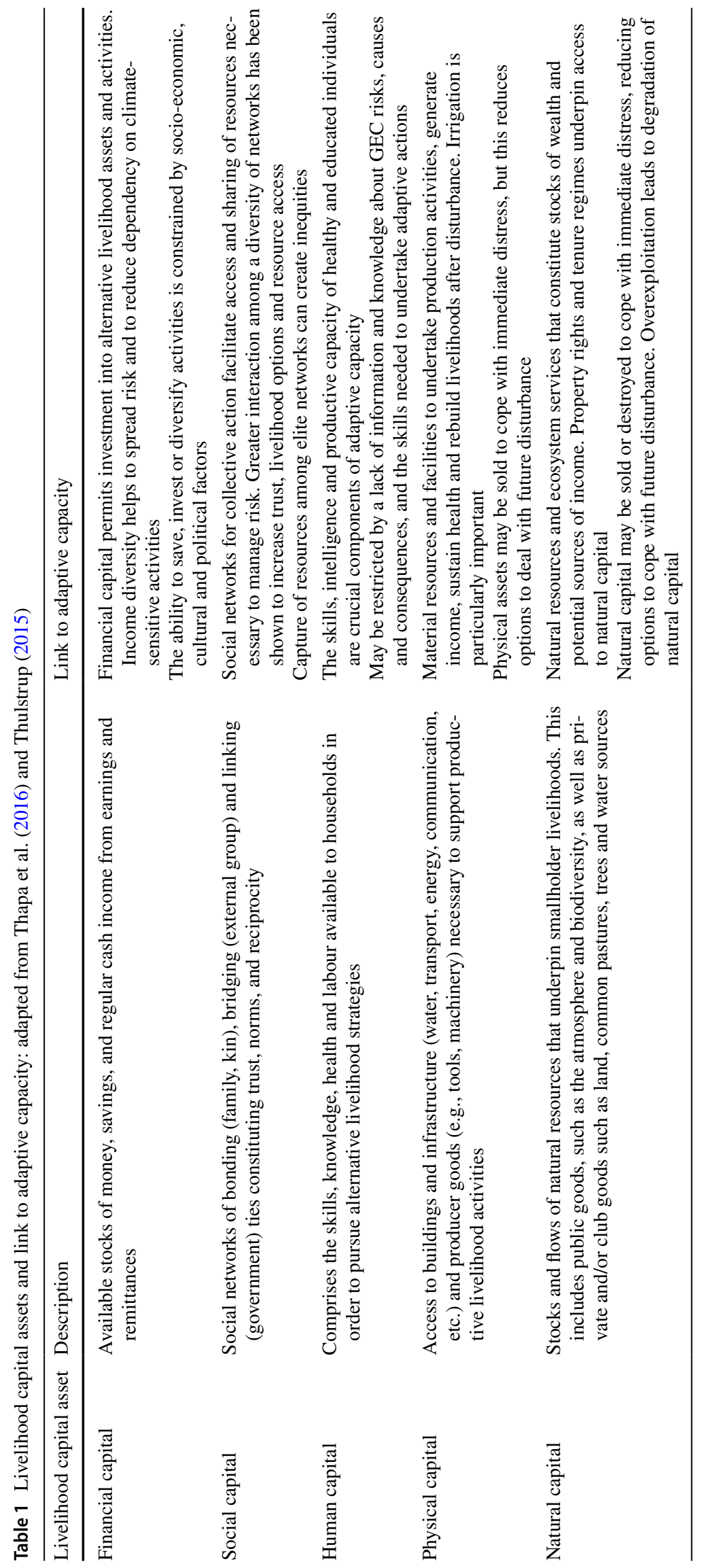


(e.g., contours, slope, altitude) (Goel 2014). Navigating such landscapes has produced unique institutional responses and adaptations to reduce risks, such as collective natural resource management to regulate, regenerate and recycle forest, water and pasture resources (Jodha 2005).

Low-intensity, risk-spreading traditional systems typical of MMA are increasingly marginalised by development policies and programmes that intensify resource use with insufficient acknowledgement of MMA specificities and needs (Ingty 2017; Jodha 2005). Cultural, political and socio-economic marginalisation manifests through low investment in infrastructure and public services, limited access to markets, technology, and information (Gerlitz et al. 2017). Increasing marginalisation is compounded by higher-than-average temperature increases being observed at high altitudes during the past century, with negative implications for food security and ecosystem services (IPCC 2014). Subsequently, larger numbers of males migrate over increasingly larger distances and longer periods, seeking waged employment in towns and cities, leaving behind women, children and elderly people who are less physically capable to manage smallholdings (FAO 2015; Satyal et al. 2017). Women undertake the primary responsibility of producing livelihoods, tending to crops, livestock and the family, and collecting fuelwood (Gururani 2014).

Neglecting mountain contexts limits smallholder options and increases vulnerability to GEC (Mishra et al. 2019). The specificities of MMA are central to the need to enhance adaptive capacity through institutions for collective action.

\section{Analytical framework for assessing adaptive capacity and SDG interactions}

Asset and process-based approaches to adaptive capacity should be addressed explicitly, simultaneously and iteratively if the SDGs are to be achieved in the context of GEC (Eakin et al. 2014). However, adaptive action is rarely discrete or stand-alone (Smit and Wandel 2006), and mainstreaming adaptive capacity into existing development planning may be necessary (Armitage 2005; Pelling 2011). Three existing development approaches have been identified for enhancing adaptive capacity (Eakin et al. 2009; Suckall et al. 2018): (i) natural hazard mitigation (e.g., early warning systems, evacuation procedures, flood defences); (ii) reducing social vulnerability (e.g., increased equity and access to markets, education, health); and (iii) increasing social-ecological resilience (e.g., sustainable natural resource management). Figure 1 illustrates the convergence among the three approaches through acknowledgement of adaptive capacity. Specifically, the interdependence of institutional processes and collective action that facilitate access to and distribution of livelihood assets. Such dynamics have implications for SDG interactions. Table 2 outlines the adaptive

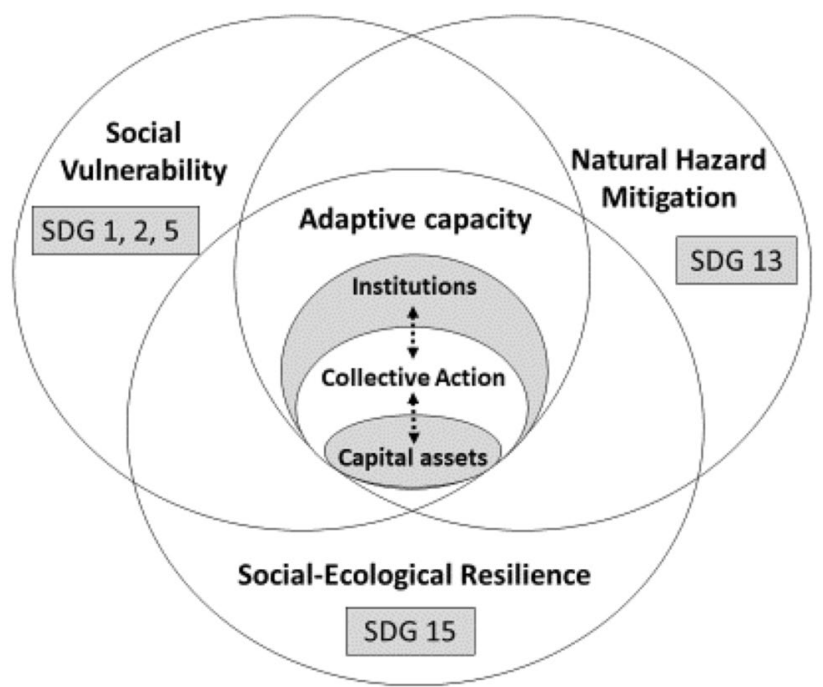

Fig. 1 The convergence of social vulnerability, natural hazard mitigation, and social-ecological resilience approaches through adaptive capacity (dotted lines represent feedback): adopted from Berman et al. (2012), Cutter et al. (2008) and Engle (2011)

capacity aspects of each approach, the contribution of each approach to the SDGs, and the inherent trade-offs among the approaches in terms of spatial and temporal scale, their goals and outcomes (Eakin et al. 2009) (Table 2). The framework helps understand the nature and type of SDG interactions through the lens of the three approaches, and to identify the inherent synergies and trade-offs of specific collective actions: i.e., those aimed at each approach that enhance process (institutional) and asset (livelihood resource) based adaptive capacity. Understanding how SDG interactions play out in MMA can help achieve sustainable mountain development and the principle of 'leave no one behind' (von Dach et al. 2016).

\section{Materials and methods}

\section{Study site selection}

This study focusses on the Saryu valley of Bageshwar district, Uttarakhand state, located in the fragile mountain system of the CIHR, remote in terms of geography, accessibility, seasonality and government oversight. The area has seasonal weather, and micro-climates that are dependent on the slope, altitude, direction, and shadows of mountain peaks. The valley falls within earthquake zone $\mathrm{V}$, the most earthquake-prone zone in India, with temperature and rainfall instability being one of the most severe in India due to climate variability and change, and compounded by deforestation, land cover and use change (Goel 2014; Mishra et al. 


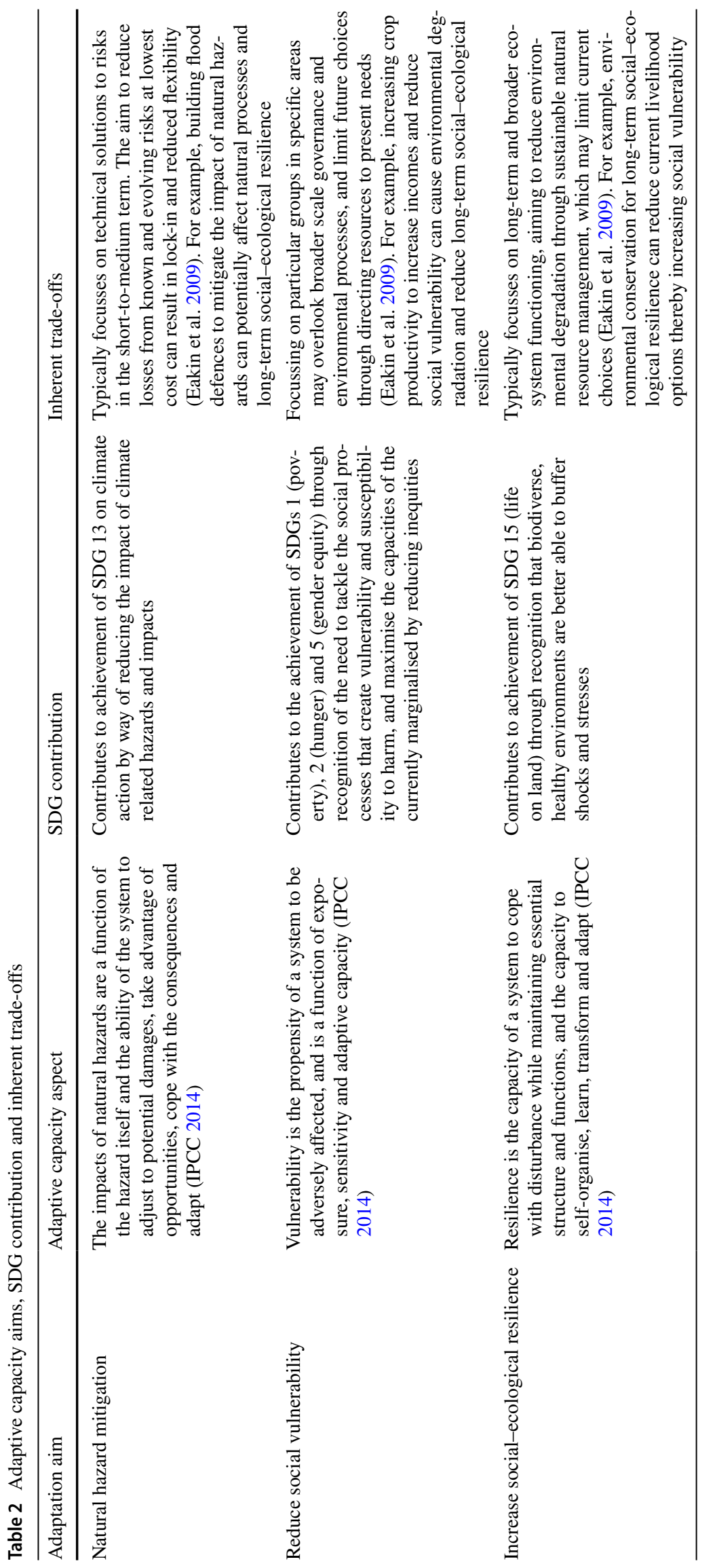


2019; IPCC 2014). Four villages were selected for study in the Saryu valley: Baret, Guler, Sumgarh and Supi (Fig. 2).

Study village locations range between 1500 and $2500 \mathrm{~m}$ asl, and are positioned on mountain ridges separated from one another by river valleys. The ridges are wooded with forests including pine, oak, bamboo, cedar, cypress, fir and rhododendron. All the villages are characterised by high rates of poverty, low development, and high dependence on rain-fed subsistence agriculture and livestock rearing. The arable land in all villages comprised low-fertility soils and small fragmented land-holdings averaging less than one hectare per household (Table 3). There are two main cropping seasons in the area. The Kharif season runs from June to October and the main crops are rice, millet, maize, pulses, groundnut, oilseeds, and mustard. The Rabi season runs from October to March and the main crops are wheat, barley, chickpeas, and pulses. Various fruits and vegetables are cultivated throughout the year. Cows and buffaloes are reared mainly for milk, and male cattle are used for ploughing the fields. Sheep and goats are reared chiefly for wool and skins. Temporary and permanent migration is common in all four villages, with nearby work on larger farms and further afield in the construction, mining, manufacturing and tourism industries, and further employment opportunities in urban areas.

Religion and ecosystem management are "...interwoven in a symbolic network of Himalayan traditions and culture" (Negi 2012 p. 273). These are expressed through informal, traditional norms, values, beliefs and taboos that are fundamental guides of social conduct in the management of natural resources in MMA of Uttarakhand (Negi 2012). Protection and propagation of resource species, regulation of harvesting, avoidance of harmful habitat modification, patch-switching to maximise overall return rates, and the dedication of sacred sites all serve to strengthen human-nature relations through a conservation ethic.

Historic patterns of migration are also key to understanding Uttarakhand culture. Movements of people from the Gangetic plains, attracted by valleys suitable for agriculture and as a place of pilgrimage and refuge, have shaped unique informal socio-cultural, religious and caste based institutions (Anand 2006). In addition, complex gendered institutions have evolved that shape women's knowledge, experience and political and economic contexts.

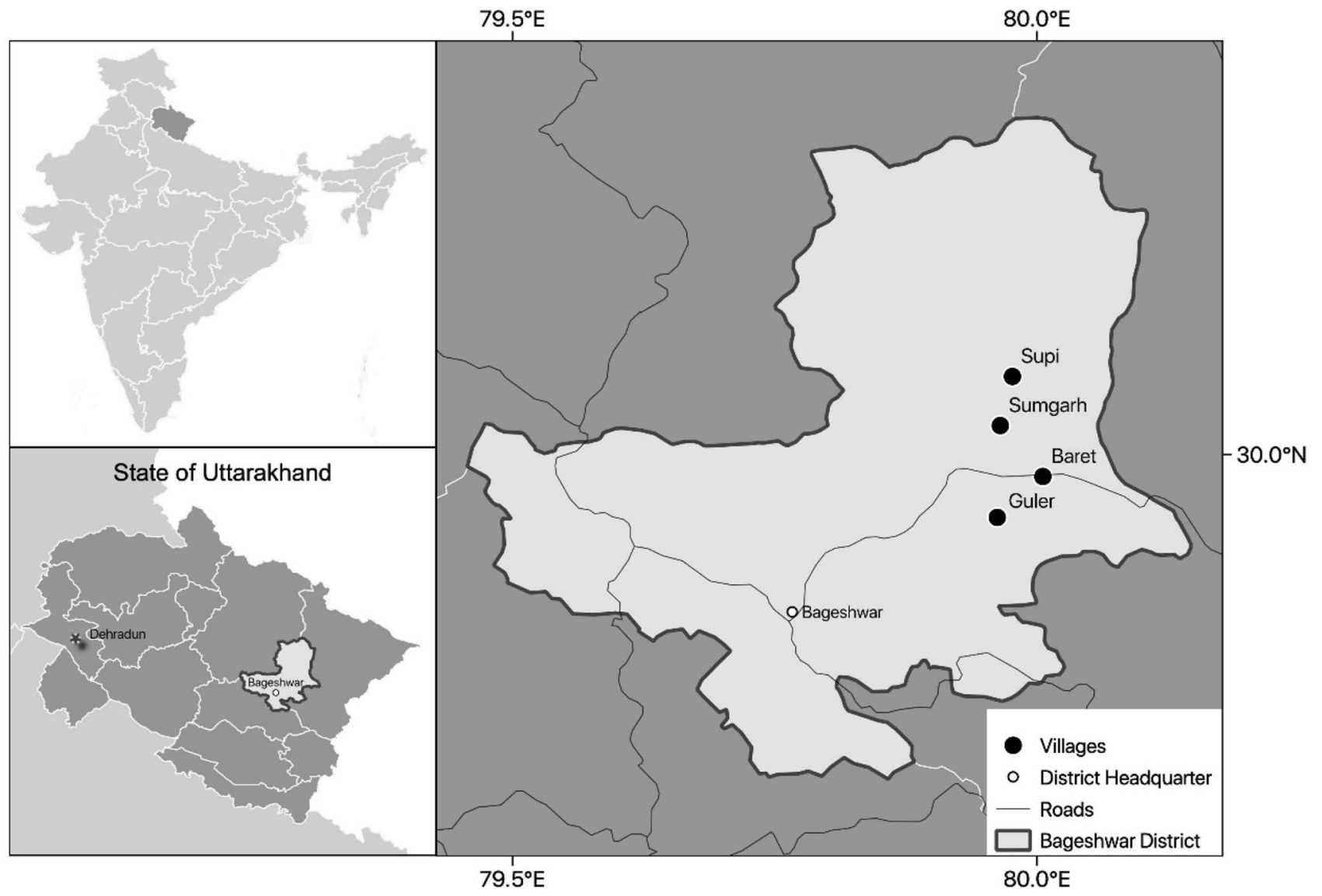

Fig. 2 Study sites in Bageshwar district, Uttarakhand state 
Table 3 Study village information (Government of India 2011)

\begin{tabular}{lllll}
\hline & Baret & Guler & Supi & Sumgarh \\
\hline Number of surveys conducted & 60 & 49 & 59 & 61 \\
\% of households surveyed & 20 & 39 & 20 & 31 \\
Total households & 298 & 125 & 304 & 198 \\
Total population & 1440 & 592 & 1701 & 859 \\
Population density $\left(p / \mathrm{km}^{2}\right.$ ) & 140 & 150 & 230 & 70 \\
Number of people from low caste/tribe & $378 / 34$ & $99 / 71$ & $646 / 0$ & $256 / 0$ \\
Number of literate individuals & 921 & 388 & 1037 & 530 \\
Total area of village (ha) & 1027 & 393 & 748 & 1167 \\
Total forest area (ha) & 200 & 118 & 406 & 807 \\
Total grazing area (ha) & 315 & 133 & 0 & 0 \\
Net sown area (ha) & 145 & 73 & 262 & 185 \\
Net sown area per household (ha) & 0.49 & 0.58 & 0.74 & 0.93 \\
Total irrigated area (ha) & 80 & 15 & 0 & 20 \\
Water access & Drinking water, springs, river, & Drinking water, & Drinking water, \\
& canal, public tanks & springs & springs & spring, canal, \\
stream & & \\
\hline
\end{tabular}

Intersecting socio-cultural contexts such as class, caste, ethnicity, and age combine with upstream, midstream and downstream mountain geographies to produce differential access to resources (Gururani 2014).

Following the 2012 flash flood disaster in Uttarakhand, the Saryu valley has been the focus of developing agency interventions aimed at facilitating collective action in order to support local livelihoods and water resource management. This study focusses on two development agency interventions in the Saryu valley: (i) the People's Science Institute's (PSI) 'Participatory Livelihoods Rehabilitation project'; and (ii) the Watershed Management Directive (WMD) 'Decentralised Watershed Development Project'. The four study villages were selected based on the degree of development agency intervention, which has resulted in different types and combination of local level collective action groups operating in each village. Baret has been the focus of PSI; Supi the focus of WMD; Sumgarh the focus of both PSI and WMD; Guler does not form part of a development cluster (i.e., a group of villages targeted by a development agency for its projects and programmes) and therefore does not have any development agency interventions in operation.

A sample of four villages is too small to make generalisations about the population of villages in the entire state or region. However, using the proximate similarity model and employing a gradient of similarity (Campbell 1986) supports the transferability of findings to mountain villages with comparable geographic and socio-economic characteristics. As each village shares relatively similar geographic and socioeconomic characteristics, selecting villages based on degree of development intervention provides the opportunity to measure indicators of adaptive capacity in villages in similar contexts but different types and combination of institutions and collective action.

\section{Institutions for collective action and actors included in the study}

For the purposes of this paper, we are particularly interested in village-level collective action facilitated by: (i) villagelevel committees, and (ii) development agency interventions. We consider these to be formal institutions, exhibiting openly codified rules communicated through official channels that are more easily changed in the short-term through policy. Informal institutions (discussed in "Study site selection"), which are tacit with no discernible centre that directs and coordinates action, are acknowledged but are not directly analysed in this paper due to their multiplicity and difficultly to influence change. The village committees of interest for this study are Mahila Mangal Dals (MMD) (village-level women's committees) and Van Panchayats (VP) (village-level forest committees) (S2). Whilst these village committees form part of the government structure, they do not operate in all the villages, depending on local authorities. Village committees typically function independently of the official Panchayati Raj Institutions (decentralised system of governance), but follow the subjects assigned to them under the Constitution. In the villages in which they operate, development agencies facilitate the creation of farmer interest groups (FIGs) and self-help groups (SHGs) (S2) to help achieve their project and programme aims (S3). Membership of FIGs and SHGs typically range from between 
5 and 20 individuals, with membership based on formal contracts and agreements among group members. FIGs and SHGs are initially unregistered entities, and may become registered through either the Societies Act (1860) for nonprofit organisations, or the Companies Act (2013) for profitmaking organisations.

Participants in village committee and development agency collective action groups, with shared interests and goals, volunteer and engage in various collective activities by pooling existing resources (i.e., financial, human, social, physical and natural) in order to gain increased access to additional resources, and to share in the resulting benefits. Types of collective activity include federations of farm producer groups, water user groups, micro-financing, dairy farming and tree planting. Community development work for constructing physical flood and erosion defences were typically implemented through either village committee or development agency groups via the National Rural Employment Guarantee Act (MNREGA).

\section{Data collection and sampling}

A mixed method approach was adopted to collect data at three different levels - household, village, and state level. At the household level, 229 households (at least $20 \%$ of the total in each village) were surveyed during the period May-June 2018 (S4). Sampling followed a two-stage approach. First, the criteria for farm selection included that they were currently active farmers (i.e., farming themselves, rather than renting their land to others to manage), and cultivating less than 5 ha of land. Households were then selected using a non-probability quota sampling technique, wherein the assembled sample had the same proportions of individuals as the entire population with respect to landholding. Landholding was selected to define quota groups as this is a locally appropriate method to reflect the socio-economic status of households. Local land measurement of nalis was used ( $1 \mathrm{ha}=50$ nalis), and four quota groups were defined in each village based on locally defined landholding sizes appropriate for mountain contexts: (i) $1-15$, (ii) $15-30$, (iii) 31-45, and (iv) 46 plus. A representative number of smallholders from each village were surveyed in each quota group by convenience sampling, whereby smallholders were approached at their homes and asked if they would agree to participate in the survey.

Focus group discussions (FGDs; $n=4$ ) (S4) were organised in each village to collect data on collective action groups operating in each village, changes in livelihood activities in living memory, and experiences and responses to shocks and stresses. For participation on the focus groups, all village members were informed on the purpose, topics, and the time required for participation, and were invited to participate in a voluntary basis. Altogether, $10-15$ people participated in each focus group comprising mixed gender, age, and ethnicity.

To help put the household and village-level data into context, semi-structured interviews (S4) with key informants $(n=15)$ were conducted with development agency representatives from local public and civic organisation development agencies, such as PSI, WMD, and the government-implemented Integrated Livelihood Support Project. Participants were selected on the basis of their knowledge and involvement in development interventions that facilitate village groups for collective action. The focus of the interview was on the institutional and stakeholder landscape concerning public and civic interventions.

\section{Data analysis}

\section{Analysing quantitative data}

The household survey (S5) covering livelihood capitals, onand off-farm livelihood diversity, and SLM were used to construct a radar chart for each village (S6). The measurement of each of the indicators used to measure livelihood capitals, on/off-farm diversity, and SLM are detailed in supplementary materials (S7).

\section{Qualitative data analysis}

Our data analysis was guided by inductive qualitative approach, which enables methodological flexibility in analysing data associated with social reality (Patton 2014). It involves detailed reading of raw data, i.e., interviews and notes from focus groups, to derive concepts and themes based on the interpretations drawn from the raw data without using any priori models or conceptions (Patton 2014).

Using this approach, data were analysed in two stages. The first stage focused on raw data with the aim of reducing, ordering and structuring the data. In this stage, notes compiled from focus groups and semi-structured interviews were read in-depth and multiple times in order to identify and cluster codes, and categorise into emerging themes. Analytic coding and themes identified in this stage included collective actions relating to natural hazard risk (e.g., community development work groups constructing flooding and erosion defences), social vulnerability (e.g., farmer federations and micro-finance groups) and social-ecological resilience (e.g., water user and tree planting groups). Identification of these themes allowed an initial understanding of the patterns that emerged from the data, and acted as the foundation for further analysis on SDG interactions. The second stage focused on identifying themes across the semi-structured interviews and focus 
groups to identify patterns. In this stage, themes were categorised and patterns were identified on the basis of collective action related to three approaches, i.e., natural hazard mitigation (SDG 13), social vulnerability (SDGs 1, 2 and 5 ), and social-ecological resilience (SDG 15). The data analysis process in this stage was based on analysis both 'within' and 'across' the semi-structured interviews and focus groups, allowing the themes to shift from individual analysis to collective analysis (Gummesson 2002). This allowed an understanding of the patterns of connections between collective actions (semi-structured interviews), and livelihood activities and strategies (focus groups) necessary to discuss the implications for collective action and SDG interactions.

\section{Adaptive capacity: livelihood capital assets}

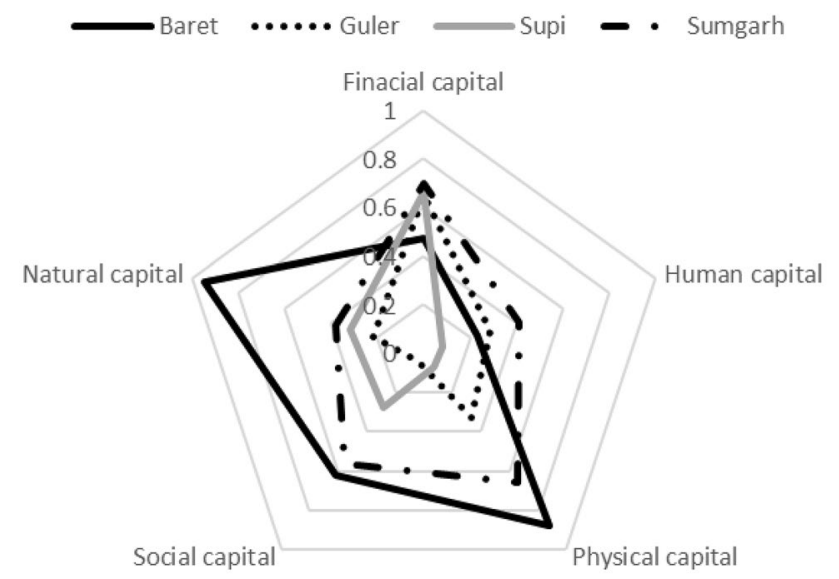

\section{Results}

\section{Livelihood capital asset access}

All villages are dominated by subsistence rain-fed agriculture, and smallholders in each study sites faced challenges due to changes in rainfall patterns, reduced farm sizes, soil fertility declines, rises in agricultural input prices, lack of finance and labour, flooding, land erosion, ineffective local administration, lack of government support, and wild animals destroying crops. Baret and Sumgarh were found to display greater overall levels of livelihood assets (Fig. 3), both of which are the focus of development agencies.

\section{Social capital}

Residents in all villages stated that there was a stronger sense of community prior to the introduction of conventional farming techniques (i.e., commercial agriculture and the use of hybrid seeds, synthetic chemical fertilizers, pesticides, and herbicides). People would support each other and share more in the past as they all faced similar challenges and socio-economic status, but modern farming and related input prices had fostered a dependency on income and a more individualistic farmer predominantly concerned with private affairs. It was believed that when people work together in present times it is to benefit themselves financially, not the community as a whole.

Baret and Sumgarh display the highest levels of social capital (Fig. 3). The high percentage of households engaging in collective action facilitated by village committees (Table 4) indicates a propensity for collective action that can be drawn on from the associated networks between farmers. PSI operate in both villages with FIGs and SHGs focusing

Fig. 3 Livelihood capital assets

Table 4 Local collective action institution household membership

\begin{tabular}{llllc}
\hline $\begin{array}{l}\text { Village institutions and collective } \\
\text { action groups }\end{array}$ & Baret (PSI) & $\begin{array}{l}\text { Guler (no. PSI } \\
\text { or WMD) }\end{array}$ & Supi (WMD) & $\begin{array}{l}\text { Sumgarh (PSI } \\
\text { and WMD) }\end{array}$ \\
\hline $\begin{array}{l}\text { Village committee } \\
\text { Mahila Mangal Dal }\end{array}$ & $90 \%$ & 0 & $42 \%$ & $67 \%$ \\
$\quad$ Van Panchayat & $23 \%$ & $6 \%$ & $22 \%$ & $39 \%$ \\
Development agency & & & $53 \%$ & $74 \%$ \\
Farmer interest group & $75 \%$ & 0 & $41 \%$ & $67 \%$ \\
Self-help group & $53 \%$ & 0 & 0 & \\
Collective action activities & & & 0 & $51 \%$ \\
Federation & $58 \%$ & 0 & $7 \%$ & $20 \%$ \\
Dairy & 0 & 0 & 0 & $34 \%$ \\
Micro-finance & 0 & 0 & $22 \%$ & 0 \\
Water user group & $48 \%$ & 0 & $41 \%$ & $23 \%$ \\
Tree planting & $93 \%$ & 0 & 0 & \\
Community development work & $97 \%$ & 0 & & \\
\hline
\end{tabular}


on federation, dairy, micro-finance and tree planting activities. Social capital was significantly lower in Guler which is not the focus of development agencies for reason state above (see Study site selection section).

\section{Financial capital}

Despite differing degrees of development agency intervention in each village, Sumgarh, Supi and Guler displayed similar levels of financial capital. These villages depended (in varying degrees) on local waged labour, temporary migration, handicrafts, and crops sales for income. Baret was found to have less financial capital due to high dependence on farming for income, in an area of steep slopes which make it highly vulnerable to landslides resulting in many households living below the poverty line. In Sumgarh, Supi and Guler there was more livestock income than Baret. Whilst Baret had the lowest level of financial capital, a high number of farmers sold crops on the market through the PSI farmer federation which had the potential to grow. Farmers from Baret stated that prior to the PSI intervention to support farmers to increase vegetable production, barely enough vegetables were grown to feed the household. However, the introduction of federations supported small surpluses of vegetables, fruits and spices to be produced and sold.

Sumgarh and Supi displayed similar levels of financial capital and proportion of households selling crops on the market. However, as Sumgarh was part of the PSI supported federation, incomes could potentially increase, whilst in Supi households sold crops on the market independently with little prospect for improvement. The differences in financial capital observed between Baret and Sumgarh (both part of the PSI federation) could be due to contextual factors, such as proximity to markets, stock of human capital, environmental characteristics, and village-level governance dynamics. Nevertheless, female villagers from PSI sites stated that SHGs had enabled women to have more control over household finances, allowing them to plan more effectively and restrict the amount of income spent by men on alcohol and unnecessary consumption. In Guler with no federation, no households sold crops on the market independently, with most households relying on local waged labour, and to a lesser degree handicrafts and temporary migration.

\section{Physical capital}

Baret displayed the highest level of physical capital access. Physical capital access correlated to the proximity of the village to block town Kapkot, with the closer villages having higher levels of physical capital (i.e., Baret, Sumgarh, Guler and Supi, respectively). PSI support for the construction of irrigation facilities in Baret has meant that farmers are increasingly aspiring to switch to cash crops, which can then be sold through the federation. Although this had increased incomes of some households, it also increased stress on water resources and diverted land from staple crops, which can increase food insecurity. Community development work for constructing physical flood and erosion defences were typically implemented through collective action facilitated by both village committees and development agencies via MNREGA. This benefitted study villages by mitigating the impacts of climate variability, and also providing additional income through waged labour.

\section{Human capital}

Households in Sumgarh displayed a notably higher level of human capital, followed by Guler and Baret both with similar levels. Even though the villages are located in remote and disaster prone areas, the level of education was higher in these villages due to relatively close proximity to the block capital town of Kapkot, where a number of higher educational facilities are located. Furthermore, as Sumgarh is a relatively high-income village, most families sent their children on to higher education. Supi had the lowest levels of human capital, which may reflect its remoteness to Kapkot. Nevertheless, development agencies facilitated collective action aiming to improve human capital through knowledge dissemination and learning about SLM, markets and business, and disaster preparation and response.

\section{Natural capital}

Baret displayed significantly greater access to natural capital compared to the other villages. This was mainly due to Baret being located in a valley comprising some flat areas, meaning that land holdings were larger than those in villages comprising more slopes. PSI aimed to promote SLM practices through collective action to improve soil fertility and increase productivity, and reduce pressure on surrounding natural resources through water saving and reduced chemical use. However, land abandonment due to increased levels of permanent migration had resulted in patches of unmanaged land, attracting weeds, pests, wild animals and fires, and making it difficult for those left behind to navigate and manage the land.

\section{Livelihood diversity and sustainable land management}

\section{Livelihood diversity}

All study villages displayed relatively similar levels of total livelihood diversity (Fig. 4). However, Baret and Sumgarh exhibited the highest level of on-farm livelihood diversity in terms of livestock owned and crops grown (Fig. 5). Supi 


\section{Adaptive capacity: diversity, SLM \& coping}

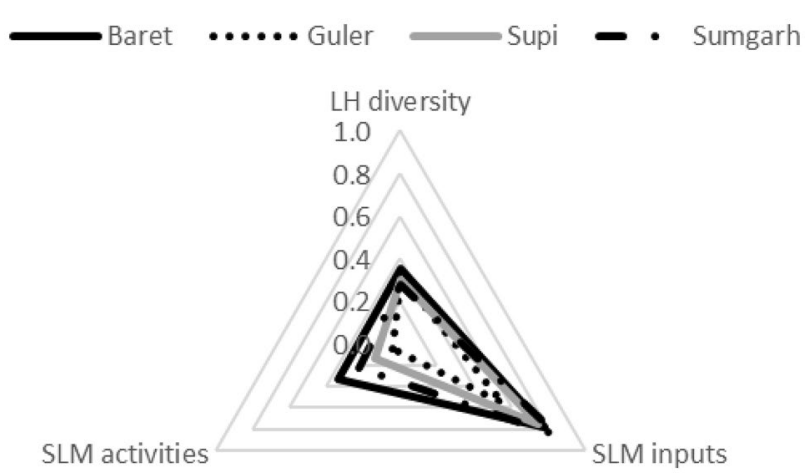

Fig. 4 Livelihood diversity, SLM activities, and SLM inputs in each village

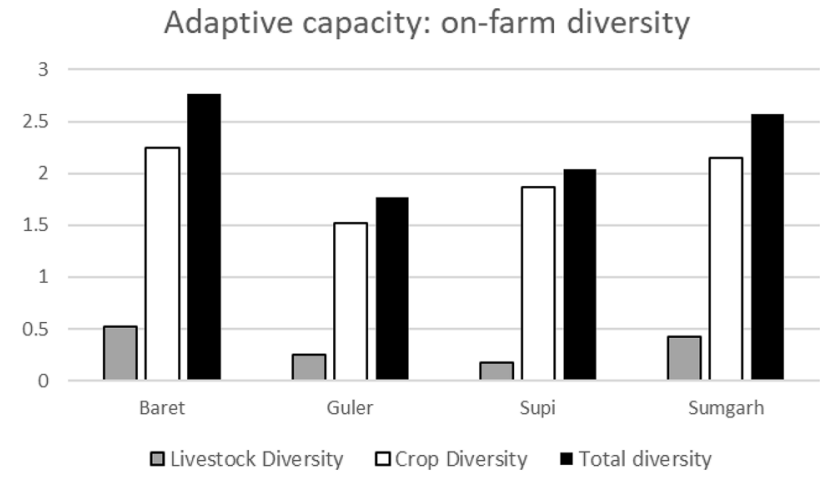

Fig. 5 On-farm livelihood diversity in each study village

displayed the next highest on-farm livelihood diversity, with Guler showing the lowest. This suggests that villages with development agencies facilitating collective action had increased livelihood diversity through the activities they promote, such as farmer federations and micro-finance for small rural enterprises, natural resource management for foraging, and irrigation to grow cash crops.

\section{Sustainable land management}

Baret and Sumgarh displayed the highest level of SLM inputs and activities (Fig. 4). PSI supported farmers in the transition to organic forms of farming, and promoted a system of crop intensification (SCI). A high volume of households also used mixed cropping and crop rotation in Baret and Sumgarh. Supi was also third for SLM inputs and activities using mixed cropping, manuring and use of traditional seeds. WMD provided hybrid seeds and chemical input equipment to farmers in Supi and Sumgarh, but farmers had to travel to the distribution centre in the next town to pick them up. Guler had the lowest level of SLM inputs and activities, which could be reflective of the lack of interaction with collective action facilitated by development agencies to share awareness of SLM practices.

\section{Discussion: collective action and SDG synergies and trade-offs}

Results illustrate each village has unique socio-environmental characteristics, implying distinct development challenges and vulnerabilities are present, and distinct kinds of adaptive capacity exist. Villages with development agency institutions facilitating collective action were shown to display greater levels of livelihood capital assets and on-farm diversity. This suggests that those villages have greater adaptive capacity linked to financial, human, social, physical and natural capitals (see Table S1). This section explores the direct contribution of each approach to adaptive capacity (i.e., natural hazard mitigation, social vulnerability and social-ecological resilience), and the inherent synergies and trade-offs between specific SDG targets and collective actions facilitated by formal village committee and development agency institutions (Table 5).

\section{Collective action for the natural hazard risk approach to adaptive capacity}

This study identified formal institutions facilitating collective action relating to flood defence construction, forest restoration, diversifying livelihoods and SLM. These actions can increase adaptive capacity and directly contribute to SDG 13 by strengthening resilience to climate related hazards (target 13.1), integrating climate change into development planning (target 13.2), and improving awareness of climate change (target 13.3). PSI facilitated collective action in response to the 2013 Uttarakhand flooding disaster, representing a shock that can stimulate adaptive governance (Walch 2018). As reflected in the collective construction of flood defences in the study villages, this can enhance physical capital through collective identification, prioritisation, planning and response to infrastructure requirements in areas exposed to climate related hazards (Bird et al. 2011). In the Alto Mayo mountainous region of Peru, development agencies facilitated collaborative infrastructure construction, utilising local knowledge of materials and structures with external technologies and techniques which minimised costs and fostered learning for locally appropriate safety standards (Schilderman 2004). Whilst our results indicate less human capital in more remote areas, collective action facilitated through formal institutions has been shown to enhance human capital through collective natural hazard mapping and vulnerability assessments, raising awareness of the causes, processes and consequences of climate change 
Table 5 The direct SDG contribution, synergies and trade-offs among the three approaches to adaptive capacity

\begin{tabular}{|c|c|c|c|c|}
\hline Adaptive capacity approach & Direct SDG contribution & Direct SDG targets & SDG synergies & SDG trade-offs \\
\hline Natural hazard mitigation & SDG13: climate change & $13.1,13.2,13.3$ & $\begin{array}{l}1.1,1.3,1.4,1.5 \\
5 a, 5 b \\
15.1,15.2,15.4,15.6,15.9\end{array}$ & $\begin{array}{l}1.1,1.4,1.5 \\
2.1,2.3,2.4 \\
5.4,5 a, 5 b \\
13 b \\
15.1,15.4,15.9\end{array}$ \\
\hline Social vulnerability & $\begin{array}{l}\text { SDG1: end poverty } \\
\text { SDG2: end hunger } \\
\text { SDG5: gender equality }\end{array}$ & $\begin{array}{l}1.1,1.2,1.3,1.4 \\
2.1,2.2,2.3,2.4 \\
5.1,5.4,5.5,5 a, 5 b\end{array}$ & $\begin{array}{l}13.1,13.3 \\
15.1,15.2,15.3,15.4,15.9\end{array}$ & $\begin{array}{l}1.2,1.4,1.5 \\
2.1,2.4,2.5, \\
5.4 \\
13.1,13.2,13 \mathrm{~b} \\
15.1,15.2,15.3, \\
15.4,15.5,15.6, \\
15.9\end{array}$ \\
\hline Social-ecological resilience & SDG15: life on land & $\begin{array}{l}15.1,15.2,15.3,15.4 \\
\quad 15.6,15.9\end{array}$ & $\begin{array}{l}1.4,1.5 \\
2.4 \\
5.4,5.5 \\
13.1\end{array}$ & $\begin{array}{l}1.1 \\
2.3 \\
5.4 \\
15.2,15.6\end{array}$ \\
\hline
\end{tabular}

(Adhikari and Taylor 2012). This supports locally appropriate risk reducing activities, such as early warning systems, evacuation and rescue procedures, first aid awareness, and use of communication equipment crucial in the aftermath of disasters. Results also suggest that formal institutions can enhance social capital by encouraging social interaction that builds networks of trust, which have been shown to increase mitigative actions, adherence to emergency procedures, and the likelihood of rescue (Dynes 2005).

Collective action for natural hazard mitigation can capture a number of synergies among SDGs. Results indicate that financial capital and livelihood diversity can be enhanced, contributing to reductions to the income dimension of poverty (target 1.1). For example, results show how formal institutions can facilitate collective action to access cash-for-work programmes constructing flood defences and repairing infrastructure (Adhikari and Taylor 2012), and can also help members re-establish income generating activities post-disaster (Petal et al. 2008). Research has shown that collective action can further build the resilience of the vulnerable (target 1.5) by facilitating equitable access to climate information (targets 1.4, 5a and 5b). Research in the mountains of Nepal (Luintel et al. 2018) also found that collective forest management, whilst integrating environmental values into development planning, sequesters carbon and mitigates the impacts of climate change by enhancing biodiversity (targets 15.1, 15.2, 15.4, 15.6, and 15.9).

Regarding trade-offs, forest restoration and flood defences can limit agricultural productivity, nutrition and incomes if implemented on arable land (targets 2.3, 2.1 and 1.1). Flood defence construction could also reduce flexibility to manage climate uncertainty through lock-in (Eakin et al. 2009) and maladaptation (Barnett and O'Neill 2010) thereby exacerbating vulnerabilities (targets 13b, 1.5 and 2.4). For example, Gunderson and Holling (2002) point out that flood defences can undermine natural processes, resulting in changes in soil and water resources that can cause drought and flooding downstream (targets 15.1, 15.4, 15.9). Politics and power can also constrain adaptive capacity (Karpouzoglou et al. 2016) resulting in uneven distribution of the benefits of flood defences and forest restoration (targets 1.4, 2.3, 5a and b), for example if they are situated to benefit certain people and not others, or on previously common property land used for local livelihoods. Finally, results showed that flood defence construction and forest restoration activities are typically delegated to women, increasing their work burden (target 5.4).

\section{Collective action for the social vulnerability approach to adaptive capacity}

This study identified FIGs and SHGs that can enhance adaptive capacity through tackling multi-dimensional aspects of poverty (target 1.2), namely: increasing farm productivity (target 2.3 ), income, savings, loans and credit (target 1.1), and enhancing gender equity (target 5a). Results show that formal institutions disseminate knowledge of SLM practices that can help stabilise income and yields (Bijman 2016) (targets 1.1 and 2.4). Formal institutions can enhance human capital, in remote study villages exhibiting low levels, through collective action that facilitates awareness and learning. For example, findings are in line with research highlighting that FIGs can provide business skills, market knowledge, quality assurance and certification (Bijman 2016), whilst SHGs can provide training in basic literacy, cognitive skills, primary healthcare, family planning, and marketing and business administration (Swain and Wallentin 2009). The enhanced social capital observed in villages with greater collective action can empower members to 
participate in wider social, economic and political life, which can reduce free-rider and elite capture problems (Bijman 2016) and support adaptive governance (SharmaWallace et al. 2018). In particular, women's involvement in public life can challenge gender discrimination (Alemu et al. 2018) and provide greater autonomy for women within and outside the household (Swain and Wallentin 2009) (targets 5.1, 5.4 and 5.5). Results indicate that women engaged in SHGs expressed greater control over household finances, increasing household investment in education, housing (target 1.2) and nutrition for children (target 2.2). Collective action can also support equitable resource access (targets 1.4, 2.3 and 5a and b) by reducing the cost of physical capital for farming (Bijman 2016), and empowerment to lobby for improved water, energy and transport infrastructure (Alemu et al. 2018). Results also indicate that collective action can increase income through improved irrigation for cash crops (targets 1.1, 1.3), whilst reducing risk by supporting crop diversification (target 1.2) and smoothing consumption (target 2.1) (Swain and Wallentin 2009).

FIGs and SHGs can capture a number of synergies among SDGs. Through collective action, members can also learn how their farming activities will be impacted by climate change, and ways to mitigate for more resilient yields and incomes (targets 13.1 and 13.3). Collective action can also increase empowerment to lobby for environmental issues, and integrate environmental values into farming practices (target 15.9) through SLM that increase biodiversity and support ecosystem services (Alemu et al. 2018) (targets 15.1, 15.2, 15.3 and 15.4). Encouraging such synergies can help address issues of power and politics that can limit adaptive governance (Karpouzoglou et al. 2016).

Trade-offs include potential inequities between members and non-members (target 1.4) that influence vulnerability (Eakin et al. 2009) (target 1.5). Results show that the conversion from staple to cash crops can increase market dependence, threaten food security (target 2.1), crop diversity (target 2.5) and long-term farm and ecosystem resilience (targets 2.4 and 13.1). Focussing on incomes can also divert attention from the multiple dimensions of poverty (target 1.2) such as health, education and well-being, and overlook gender inequities, as women are typically excluded from income generating activities (target 5.4). Prioritising income and productivity (target 15.9) were also shown to degrade water, grazing and forest resources (targets 15.1, 15.2, 15.3, 15.4 and 15.5). This results in the loss of a safety net for the most marginalised (target 15.6), reducing their ability to cope with disturbance (Thulstrup 2015) (targets 1.5 and 13b), as well as contributing to climate change through reduced carbon sequestration (target 13.2).

\section{Collective action for the social-ecological resilience approach to adaptive capacity}

The identified collective actions related to forest restoration, WUA and SLM practices can enhance adaptive capacity and directly support SDG 15 by supporting: international environmental agreements (target 15.1); the sustainable management of forests (target 15.2), land (target 15.3), mountains (target 15.4) and biodiversity (target 15.1); and the equitable access to natural resources (target 15.6) via the integration of environment in development planning (target 15.9). Results show that FIGs promoting SLM can enhance human capital by encouraging collaboration and the integration of local and expert knowledge of ecosystem structure and functions (target 15.9). This raises awareness of the causes and consequences of environmental issues, and support collaboration for locally appropriate SLM practices and adaptive governance (Armitage 2005; Gunderson and Holling 2002; Sharma-Wallace et al. 2018). Results also indicate that through Van Panchayats, collective action can enhance social capital and trust to develop appropriation and provision rules in response to changing environments, in line with research on community forests in Nepal (Nagendra et al. 2007). Conversely, Cox (2014) shows overexploitation and tragedy of the commons occurs when trust is eroded. Child and Barnes (2010) also argue that collective action enhances the potential for political transformation through locally and collectively administered democracy, equity, transparency and accountability (target 15.6).

Forest restoration, WUA and SLM practices capture a number of SDG synergies. Results indicate that collective SLM practices can stabilise crop yields, and therefore contribute to reducing hunger (target 2.4). As results suggest, collective natural resource management promote healthy environments, which research shows experience less severe climate impacts (Cutter et al. 2008) (target 13.1). Collective natural resource management can further reduce vulnerability and risk (target 1.5) by enhancing equitable resource access (target 1.4) and increasing livelihood diversification through provision of fodder, fuelwood, water and grazing, some of which may be sold for cash to supplement household income (Gerlitz et al. 2017). Formal institutions can also enhance the participation and recognition of women's understandings and reliance on natural resources (target 5.4 and 5.5).

SDG trade-offs regarding forest restoration, WUA and SLM centre on the prioritisation of broader environmental spatial and temporal scales. Balancing current levels of environmental exploitation with future needs (Eakin et al. 2009) can reduce farm productivity (target 2.3) and income (target 1.1). For example, a shift away from agriculture for environmental conservation may bring future benefits, but would entail current social and economic costs for those reliant on 
agriculture (Folke et al. 2002). It is also suggested that SLM requires more farmland to compensate for reduced yields, at least initially, providing an incentive to encroach farmland into forested areas (target 15.2). Results suggest that financial benefits and costs are not always distributed evenly (target 15.6), as group membership costs are relatively higher for poorer households (Adhikari and Taylor 2012), and elite capture can occur if institutions are poorly designed (Child and Barnes 2010). As previously discussed, forest restoration was found to be typically delegated to women, increasing their work burden (target 5.4).

\section{Conclusion}

The findings presented here provide a snapshot of four MMA villages in the CIHR, and illustrate quantitatively that each village has unique characteristics, implying that distinct development challenges and vulnerabilities are present, distinct kinds of adaptive capacity exist, and suggesting that different kinds of collective action facilitated by formal institutions are appropriate. We have discussed how collective action can increase social interaction and resource sharing in MMA comprising low income levels, lack of bargaining power and market access, and harsh landscapes with high sensitivity to climate change. Identifying and analysing collective action in MMA focused on the three approaches to adaptive capacity: natural hazard mitigation (SDG13), social vulnerability (SDG1, 2 and 5), and social-ecological resilience (SDG15). This contributes to our understanding of how to capture the synergies while limiting the trade-offs among SDGs while enhancing adaptive capacity in MMA.

Local collective action facilitated by formal institutions operates within specific socio-cultural, political, economic and environmental contexts of MMA. It is crucial to acknowledge that each context shapes the parameters, dynamics, pathways and degree of synergies and trade-offs among the SDGs. There are no 'one size fits all' solutions, and designing locally appropriate collective action will be necessary for achieving the SDGs in the context of GEC. This study has provided initial insights into the characteristics and specific SDG synergies and trade-offs occurring in MMA. This has highlighted the necessity for formal institutions to facilitate collective action and co-production in the identification, prioritisation, design and implementation of sustainable solutions to the challenges facing smallholders in MMA. In doing so, development agencies should ensure they acknowledge pre-existing formal and informal institutions that communities recognise and identify with, and which enable and constrain adaptive capacity and achievement of the SDGs.

This study has explored specific characteristics, challenges, vulnerabilities and capacities among villages in
MMA, whilst recognising the importance of local informal institutions. However, it is limited in only providing analysis of collective action facilitated through formal institutions, and a snapshot in time of adaptive capacity at the aggregate village level. As development agencies have come under criticism for applying blue-print solutions and overlooking the historical, socio-cultural and political dynamics that enable and constrain sustainable development, future research would benefit from further analysis of the interaction between formal and informal institutional processes in MMA, and how they shape human-environment interactions from the individual and household perspective.

Acknowledgements This research was supported by the Sussex Sustainability Research Programme, University of Sussex, UK. We are grateful to the staff of the People's Science Institute, particularly Puran Bartwal. We are also grateful to the communities of Baret, Sumgarh, Supi and Guler for their engagement and enthusiasm throughout this work (Grant No. SSRP2016-017).

Open Access This article is licensed under a Creative Commons Attribution 4.0 International License, which permits use, sharing, adaptation, distribution and reproduction in any medium or format, as long as you give appropriate credit to the original author(s) and the source, provide a link to the Creative Commons licence, and indicate if changes were made. The images or other third party material in this article are included in the article's Creative Commons licence, unless indicated otherwise in a credit line to the material. If material is not included in the article's Creative Commons licence and your intended use is not permitted by statutory regulation or exceeds the permitted use, you will need to obtain permission directly from the copyright holder. To view a copy of this licence, visit http://creativecommons.org/licenses/by/4.0/.

\section{References}

Adger WN (2003) Social capital, collective action, and adaptation to climate change. Econ Geogra 79(4):387-404

Adhikari B, Taylor K (2012) Vulnerability and adaptation to climate change: a review of local actions and national policy response. Clim Dev 4(1):54-65. https://doi.org/10.1080/17565 529.2012.664958

Agrawal A (2008) The role of local institutions in adaptation to climate change. Social dimensions of climate change. Social Development Department, The World Bank, Washington DC

Alemu SH, Van Kempen L, Ruben R (2018) Women empowerment through self-help groups: the bittersweet fruits of collective apple cultivation in highland ethiopia. J Hum Dev Capab 19(3):308330. https://doi.org/10.1080/19452829.2018.1454407

Anand MR (2006) Understanding the socio-cultural experiences of pahari folk: the jagar gathas of kumaon and garhwal. Indian Folk Res J 3(6):93-103

Armitage D (2005) Adaptive capacity and community-based natural resource management. Environ Manage 35(6):703-715. https:// doi.org/10.1007/s00267-004-0076-z

Barnett J, O'Neill S (2010) Maladaptation. Glob Environ Change Hum Policy Dimens 20(2):211-213. https://doi.org/10.1016/j.gloen vcha.2009.11.004

Berman R, Quinn C, Paavola J (2012) The role of institutions in the transformation of coping capacity to sustainable adaptive 
capacity. Environ Dev 2:86-100. https://doi.org/10.1016/j.envde v.2012.03.017

Bettini Y, Brown RR, de Haan FJ (2015) Exploring institutional adaptive capacity in practice: examining water governance adaptation in Australia. Ecol Soc. https://doi.org/10.5751/es07291-200147

Bijman J (2016) The changing nature of farmer collective action: introduction to the book. In: Bijman J, Muradian R, Schuurman J (eds) Cooperatives, Economic Democratization and Rural Development. Edward Elgar Publishers, Cheltenham

Bird DK, Chague-Goff C, Gero A (2011) Human response to extreme events: a review of three post-tsunami disaster case studies. Aust Geogr 42(3):225-239. https://doi.org/10.1080/00049 182.2011 .595670

Bowen KJ, Cradock-Henry NA, Koch F, Patterson J, Hayha T, Vogt J, Barbi F (2017) Implementing the "Sustainable Development Goals": towards addressing three key governance challenges collective action, trade-offs, and accountability. Curr Opin Environ Sustain 26-27:90-96. https://doi.org/10.1016/j.cosus t.2017.05.002

Butler JRA, Bohensky EL, Suadnya W, Yanuartati Y, Handayani T, Habibi P, Puspadi K, Skewes TD, Wise RM, Suharto I, Park SE, Sutaryono Y (2016) scenario planning to leap-frog the sustainable development goals: an adaptation pathways approach. Clim Risk Manag 12:83-99. https://doi.org/10.1016/j. crm.2015.11.003

Campbell DT (1986) Relabelling internal and external validity for the applied social sciences. In: Trochim W (ed) Advances in quasiexperimental design and analysis. Jossey-Bass, San Francisco, pp 67-67

Chambers R, Conway G (1992) Sustainable rural livelihoods: practical concepts for the 21st century. IDS Discussion Paper 296. Sussex, Brighton, UK

Child B, Barnes G (2010) The conceptual evolution and practice of community-based natural resource management in southern Africa: past, present and future. Environ Conserv 37:3. https:// doi.org/10.1017/S0376892910000512

Cox M (2014) Understanding large social-ecological systems: introducing the SESMAD project. Int J Commons 8(2):265-276. https:// doi.org/10.18352/ijc.406

Cutter SL, Barnes L, Berry M, Burton C, Evans E, Tate E, Webb J (2008) A place-based model for understanding community resilience to natural disasters. Glob Environ Change 18(4):598-606. https://doi.org/10.1016/j.gloenvcha.2008.07.013

Dynes R (2005) Community social capital as the primary basis for resilience. University of Delaware, Disaster Res Cent, Newark

Eakin H, Tompkins EL, Nelson DR, Anderies JM (2009) Hidden costs and disparate uncertainties: trade-offs in approaches to climate policy. In: Adger NW, Lorenzoni I, Brien OK (eds) Adapting to climate change: thresholds, values, and governance. Cambridge University Press, Cambridge

Eakin HC, Lemos MC, Nelson DR (2014) Differentiating capacities as a means to sustainable climate change adaptation. Glob Environ Change Hum Policy Dimen 27:1-8. https://doi.org/10.1016/j. gloenvcha.2014.04.013

Ellis F (1998) Household strategies and rural livelihood diversification. J Dev Stud 35(1):1-38. https://doi.org/10.1080/0022038980 8422553

Engle NL (2011) Adaptive capacity and its assessment. Global Environ Change Hum Policy Dimens 21(2):647-656. https://doi. org/10.1016/j.gloenvcha.2011.01.019

Fazey I, Wise RM, Lyon C, Câmpeanu C, Moug P, Davies TE (2016) Past and future adaptation pathways. Clim Dev 8(1):26-44. https ://doi.org/10.1080/17565529.2014.989192

Folke C, Carpenter S, Elmqvist T, Gunderson L, Holling C, Walker B (2002) Resilience and sustainable development: building adaptive capacity in a world of transformations. Ambio 31(5):437-440
Gerlitz J, Macchi M, Brooks N, Pandey R, Banerjee S, Jha SK (2017) The Multidimensional Livelihood Vulnerability Index-an instrument to measure livelihood vulnerability to change in the Hindu Kush Himalayas. Clim Dev 9(2):124-140. https://doi. org/10.1080/17565529.2016.1145099

Goel RK (2014) Tunnelling through weak and fragile rocks of Himalayas. Int J Min Sci Technol 24(6):783-790. https://doi. org/10.1016/j.ijmst.2014.10.008

Gomez-Echeverri L (2018) Climate and development: enhancing impact through stronger linkages in the implementation of the Paris Agreement and the Sustainable Development Goals (SDGs). Philos Trans R Soc A. https://doi.org/10.1098/rsta.2016.0444

Government of India (2011) Provisional results of 2011 census. State Directorate of Census in Delhi, Mumbai

Gummesson E (2000) Qualitative methods in management research. Sage Publications, Thousand Oaks

Gunderson LH, Holling CS (2002) Panarchy: understanding transformations in human and natural systems. Island Press, Washington, DC

Gupta J, Termeer CJAM, Klostermann J, Meijerink SV (2010) The adaptive capacity wheel: a method to assess the inherent characteristics of institutions to enable the adaptive capacity of society. Environ Sci Policy. https://doi.org/10.1016/j.envsci.2010.05.006

Gururani S (2014) Geographies that make resistance": remapping the politics of gender and place in Uttarakhand. India. J Nepal Himal Stud 34(1):12

Helmke G, Levitsky S (2004) Informal institutions and comparative politics: a research agenda. Perspect Pol 2(4):725-740

Ingty T (2017) High mountain communities and climate change: adaptation, traditional ecological knowledge, and institutions. Clim Change 145:41-55. https://doi.org/10.1007/s10584-017-2080-3

IPCC (2014) Summary for policymakers. In: Edenhofer O, PichsMadruga R, Sokona Y, Farahani E, Kadner S, Seyboth K, Adler A, Baum I, Brunner S, Eickemeier P, Kriemann B, Savolainen J, Schlömer S, von Stechow C, Zwickel T, Minx JC (eds) Climate change 2014: mitigation of climate change. Contribution of working group III to the fifth assessment report of the intergovernmental panel on climate change. Cambridge University Press, Cambridge, United Kingdom and New York, NY, USA

Ireland P, Thomalla F (2011) The role of collective action in enhancing communities' adaptive capacity to environmental risk: an exploration of two case studies from Asia. PLOS Curr Disasters Ed. https ://doi.org/10.1371/currents.RRN1279

Jodha N (2005) Adaptation strategies against growing environmental and social vulnerabilities in mountain areas. Himal J Sci 3(5):3342. https://doi.org/10.3126/hjs.v3i5.459

Karpouzoglou T, Dewulf A, Clark J (2016) Advancing adaptive governance of social-ecological systems through theoretical multiplicity. Environ Sci Policy 57:1-9. https://doi.org/10.1016/j.envsc i.2015.11.011

Luintel H, Bluffstone RA, Scheller RM (2018) The effects of the Nepal community forestry program on biodiversity conservation and carbon storage. PLoS One. https://doi.org/10.1371/journ al.pone. 0199526

Mishra A, Appadurai AN, Choudhury D, Regmi BR, Kelkar U, Alam M, Chaudhary P, Mu SS, Ahmed AU, Lotia H, Fu C, Namgyel $\mathrm{T}$, Sharma U (2019) Adaptation to climate change in the hindu kush Himalaya: stronger action urgently needed. In: Wester P, Mishra A, Mukherji A, Shrestha A (eds) The Hindu Kush Himalaya Assessment. Springer, Cham. https://doi.org/10.1007/9783-319-92288-1_13

Nagendra H, Pareeth S, Bhawna SM, Schweik C, Adhikari K (2007) Forest fragmentation and regrowth in an institutional mosaic of community, government and private ownership in Nepal. Landsc Ecol 23(1):41-54 
Negi CS (2012) Culture and biodiversity conservation: case studies from Uttarakhand, Central Himalaya. Indian J Tradit Knowl 11(2):273-278

Nilsson M, Chisholm E, Griggs D, Howden-Chapman P, McCollum D, Messerli P, Stafford Smith S (2018) Mapping interactions between the sustainable development goals: lessons learned and ways forward. Sustain Sci 13(6):1489-1503. https://doi.org/10.1007/s1162 5-018-0604-z

North DC (1990) Institutions, institutional change, and economic performance. Cambridge University Press, Cambridge, New York

Ostrom E (1990) Governing the commons: the evolution of institutions for collective action. Cambridge University Press, Cambridge

Pandey R, Maithani N, Aretano R, Zurlini G, Archie KM, Gupta AK, Pandey VPS (2016) Empirical assessment of adaptation to climate change impacts of mountain households: development and application of an Adaptation Capability Index. J Mt Sci 13(8):15031514. https://doi.org/10.1007/s11629-015-3499-5

Patton MQ (2014) Qualitative research and evaluation methods. Sage Publications, Thousand Oaks

Pelling M (2011) Adaptation to climate change: from resilience to transformation. Routledge, London

Pelling M, High C (2005) Understanding adaptation: what can social capital offer assessments of adaptive capacity? Glob Environ Change Hum Policy Dimens 15(4):308-319. https://doi. org/10.1016/j.gloenvcha.2005.02.001

Petal M, Paci-Green R, Kelman I, Shaw R, Dixit AM (2008) Community-based construction for disaster risk reduction. In: Bosher LS (ed) Hazards and the built environment: attaining built-in resilience. Taylor \& Francis, London, pp 191-217

Reed MS, Podesta G, Fazey I, Geeson N, Hessel R, Hubacek K, Thomas AD (2013) Combining analytical frameworks to assess livelihood vulnerability to climate change and analyse adaptation options. Ecol Econ 94:66-77. https://doi.org/10.1016/j.ecole con.2013.07.007

Satyal P, Shrestha K, Ojha H, Vira B, Adhikari J (2017) A new Himalayan crisis? Exploring transformative resilience pathways. Environ Dev 23:47-56. https://doi.org/10.1016/j.envdev.2017.02.010

Schilderman T (2004) Adapting traditional shelter for disaster mitigation and reconstruction: experiences with community-based approaches. Build Res Inform 32(5):414-426. https://doi. org/10.1080/0961321042000250979

Scoones I (1998) Sustainable rural livelihoods: a framework for analysis. IDS Working Paper 72. Sussex, Brighton, UK
Sharma-Wallace L, Velarde SJ, Wreford A (2018) Adaptive governance good practice: show me the evidence! J Environ Manage 222(May):174-184. https://doi.org/10.1016/j.jenvm an.2018.05.067

Smit B, Wandel J (2006) Adaptation, adaptive capacity and vulnerability. Glob Environ Change Hum Policy Dimens 16(3):282-292. https://doi.org/10.1016/j.gloenvcha.2006.03.008

Suckall N, Tompkins EL, Nicholls RJ, Kebede AS, Lazar AN, Hutton C, Mensah A (2018) A framework for identifying and selecting long term adaptation policy directions for deltas. Sci Total Environ 633:946-957. https://doi.org/10.1016/j.scitotenv.2018.03.234

Swain BR, Wallentin F (2009) Does microfinance empower women? Evidence from self-help groups in India. Int Rev Appl Econ 23(5):541-556

Tanner T, Lewis D, Wrathall D, Bronen R, Cradock-Henry N, Huq S, Lawless C, Nawrotzki R, Prasad V, Rahman MA, Alaniz R, King K, McNamara K, Nadiruzzaman M, Henly-Shepard S, Thomalla F (2015) Livelihood resilience in the face of climate change. Nat Clim Change 5:23-26. https://doi.org/10.1038/nclimate2431

Thapa B, Scott C, Wester P, Varady R (2016) Towards characterizing the adaptive capacity of farmer-managed irrigation systems: learnings from Nepal. Curr Opin Environ Sustain 21:37-44. https://doi. org/10.1016/j.cosust.2016.10.005

Thulstrup AW (2015) Livelihood resilience and adaptive capacity: tracing changes in household access to capital in Central Vietnam. World Dev 74:352-362. https://doi.org/10.1016/j.world dev.2015.05.019

Tompkins EL, Adger WN (2004) Does adaptive management of natural resources enhance resilience to climate change? Ecol Soc 9(2):10

von Dach S, Bachmann F, Borsdorf A, Kohler T, Jurek M, Sharma E (2016) Investing in sustainable mountain development. Opportunities, resources and benefits. Centre for development and environment (CDE). University of Bern, Switzerland

Walch C (2018) Adaptive governance in the developing world: disaster risk reduction in the State of Odisha, India. Clim Dev. https://doi. org/10.1080/17565529.2018.1442794

Publisher's Note Springer Nature remains neutral with regard to jurisdictional claims in published maps and institutional affiliations. 